\title{
Surgery for elderly patients with resectable pancreatic cancer, a comparison with non- surgical treatments: a retrospective study outcomes of resectable pancreatic cancer
}

\author{
Hyeong Min Park, Sang-Jae Park', Sung-Sik Han and Seoung Hoon Kim
}

\begin{abstract}
Background: We designed a retrospective study to compare prognostic outcomes based on whether or not surgical resection was performed in elderly patients aged( $\geq 75$ years) with resectable pancreatic cancer.

Methods: We retrospectively analyzed 49 patients with resectable pancreatic cancer (surgery group, resection was performed for 38 cases; no surgery group, resection was not performed for 11 cases) diagnosed from January 2003 to December 2014 at the National Cancer Center, Korea.

Results: There was no significant difference in demographics between the two groups. The surgery group showed significantly better overall survival after diagnosis than the no surgery group (2-year survival rate, $40.7 \%$ vs. 0\%; logrank test, $p=0.015$ ). Multivariate analysis revealed that not having undergone surgical resection [hazard ratio (HR) 2.412, $P=0.022$ ] and a high Charlson comorbidity index (HR 5.252, $P=0.014$ ) were independent prognostic factors for poor overall survival in elderly patients with early stage pancreatic cancer.

Conclusions: In the present study, surgical resection resulted in better prognosis than non-surgical resection for elderly patients with resectable pancreatic cancer. Except for patients with a high Charlson comorbidity index, an aggressive surgical approach seems to be beneficial for elderly patients with resectable pancreatic cancer.
\end{abstract}

Keywords: Pancreatic cancer, Elderly patient, Surgery, Non-surgical treatment

\section{Background}

Pancreatic cancer is one of the most malignant diseases and its prognosis is dismal. In contrast to the steady increase in survival for most cancers, advances have been slow for pancreatic cancers, for which the 5-year relative survival is currently $8 \%$. This low survival rate for which 5 -year survival is $2 \%$ is partly due to the high rate of an advanced stage at the time of diagnosis [1].

Only complete resection of the lesion provides a chance at cure. However, the survival rates following surgery for pancreatic cancer remain poor and have improved only marginally in recent decades $[2,3]$. In

\footnotetext{
* Correspondence: spark@ncc.re.kr

Presented to the 12th biennial Congress of the European-African Hepato-

Pancreato-Biliary Association, Mainz, Germany, June 2017

Department of Surgery, Center for Liver and Pancreatobiliary Cancer,

National Cancer Center, 323, Ilsan-ro, Ilsandong-gu, Goyang-si, Gyeonggi-do,

South Korea
}

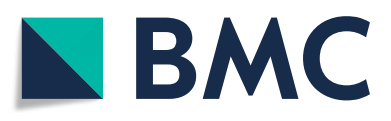

(0) The Author(s). 2019 Open Access This article is distributed under the terms of the Creative Commons Attribution 4.0 International License (http://creativecommons.org/licenses/by/4.0/), which permits unrestricted use, distribution, and

reproduction in any medium, provided you give appropriate credit to the original author(s) and the source, provide a link to the Creative Commons license, and indicate if changes were made. The Creative Commons Public Domain Dedication waiver (http://creativecommons.org/publicdomain/zero/1.0/) applies to the data made available in this article, unless otherwise stated.

elderly patients, pancreatic cancer is associated with higher perioperative mortality and morbidity rates, higher requirement of an intensive care unit stay, increased length of hospital stay, and higher rates of hospital readmission after pancreatectomy [4-8]. Recently, in contrast to the existing theory, some authors assert justification of surgical resection for pancreatic cancer in selected elderly patients. Brahmbhat et al. reported that although elderly patients had a significantly higher postoperative morbidity rates compared with younger patients, age was not associated with an increased risk of 90-day mortality following pancreatic resection [9]. Furthermore, no difference in severe morbidity and mortality rates based on the age was reported a study by Okabayashi et al. [10]. 
Few studies have compared the relative benefits of elderly patients having and not having undergone surgical resection for pancreatic cancer.

To the best of our knowledge, there is no study comparing outcomes in elderly patients with resectable pancreatic cancer having and not having undergone surgical resection except the study by Marmor et al. reported that compared with chemotherapy, surgical resection is associated with a very small survival benefit in elderly patients (aged $\geq 80$ years with lymph node metastasis) [11]. Thus, in this retrospective study, we compared prognostic results of undergoing vs. not undergoing surgical resection and identified factors related to prognosis in elderly patients with resectable pancreatic cancer.

\section{Methods}

\section{Study population and data collection}

In this retrospective study, we defined patients aged $\geq 75$ years as the elderly. We reviewed the medical records of patients diagnosed with pancreatic cancer at the $\mathrm{Na}$ tional Cancer Center in Korea between January 2003 and December 2014 to assess the impact of surgical resection on prognosis. Patients were stratified into two groups based on whether they underwent surgical resection or not. AJCC stage was clinically determined at the time of diagnosis based on pretreatment radiological imaging, including computed tomography $(\mathrm{CT})$, magnetic resonance imaging (MRI) with or without positron emission tomography (PET). All patients enrolled in this study were operable if they (1) did not have severe comorbidities or cognitive impairment, (2) were expected to show extended prognosis following surgery, (3) had an acceptable functional status, and (4) had no advanced tumors, including distant metastasis. As a result, elderly patients with resectable pancreatic cancer (AJCC stage I or II) were enrolled in this study. The Eastern Cooperative Oncology Group (ECOG) performance status (PS) and the updated Charlson comorbidity indices system were available for all patients [12-14]. Because cancer is the disease of interest, it was not included in the Charlson comorbidity index. The chemotherapy regimen for resectable pancreatic cancer at our institution comprises gemcitabine-based therapy with or without the use of other drugs. The administration of chemotherapy was defined as completed at least 1 cycle of chemotherapy. The chemotherapy in the 'Surgery group' was all conducted as adjuvant therapy.

\section{Follow-up and assessment}

Follow-up evaluation included tumor assessment by chest and abdominal-pelvic CT, tumor marker levels, and other laboratory tests (complete blood cell count, electrolytes, liver function test, and renal function test). Follow-up data were obtained via medical records or telephone contact up to December 2016. The primary end-point was overall survival (OS) in patients with resectable pancreatic cancer after diagnoses compared between the surgery and no surgery groups. The secondary end point of the study was identification of factors indicating survival. In addition, we evaluated the postoperative outcomes of patients who underwent surgical resection. Postoperative morbidities were defined according to the Clavien-Dindo (C-D) classification, and severe complications were limited to C-D classification III or IV [15]. Postoperative recurrence was determined based on CT and/or PET.

\section{Statistical analysis}

The collected data were analyzed using IBM SPSS version 22.0 (IBM Corp., Armonk, NY, USA). OS was analyzed using the Kaplan-Meier method, and the survival difference between the surgery and no surgery groups was compared using the log-rank test. Differences between continuous variables were analyzed using student's t-test. Categorical variables were compared using Pearson's chi-square test. The cumulative survival rate and univariate analysis for survival were analyzed using the Kaplan-Meier method, and the log-rank test was used to compare significant differences. To investigate the combined effects of different variables on survival, Cox's proportional hazards regression model was used. For all tests, a $p$-value of less than 0.05 was considered significant corresponding to a $95 \%$ confidence interval (95\% CI).

\section{Results}

\section{Patients}

Among 1611 patients who were diagnosed with pancreatic cancer at the National Cancer Center in Korea between January 2003 and December 2014, the number of elderly patients (aged $\geq 75$ years) was 290. Patients with advanced pancreatic cancer $(n=234)$ were excluded. Furthermore, patients with simultaneous diagnosis of another malignant disease $(n=3)$ or a history of another malignant disease $(n=4)$ were excluded. Finally, 49 patients with resectable pancreatic cancer were enrolled in this study. Thirthy-eight patients who underwent surgical resection for pancreatic cancer were categorized in the surgery group and 11 patients who did not undergo surgical resection were categorized in the no surgery group. There were 32 men and 17 women with a median age of 78 years (range: $75-87$ years). In the surgery group, a conventional Whipple's operation (PD) was performed in $6(12.2 \%)$ patients, pylorus-preserving pancreaticoduodenectomy (PPPD) in 16 (32.7\%) patients, total pancreatectomy (TP) in $4(8.2 \%)$ patients, and distal pancreatectomy (DP) in $12(24.5 \%)$ patients. Among the 11 patients in the no surgery group, 3 patients could not 
Table 1 Characteristics of patients with early stage pancreatic cancer $(N=49)$

\begin{tabular}{|c|c|c|c|}
\hline Factors & $\begin{array}{l}\text { Surgery } \\
(N=38)\end{array}$ & $\begin{array}{l}\text { No surgery } \\
(N=11)\end{array}$ & $P$ value \\
\hline Sex & & & .55 \\
\hline Male & $24(63.2 \%)$ & $8(72.7 \%)$ & \\
\hline Female & $14(36.8 \%)$ & $3(27.3 \%)$ & \\
\hline Age (mean, range) & $78(75-87)$ & $80(75-86)$ & .07 \\
\hline BMI (mean, range) & $21.8(17.5-26.8)$ & $22.0(17.4-25.4)$ & .81 \\
\hline Smoking & & & .06 \\
\hline Yes & $9(23.7 \%)$ & $5(55.6 \%)$ & \\
\hline No & $29(76.3 \%)$ & $4(44.4 \%)$ & \\
\hline Alcohol & & & .46 \\
\hline Yes & $12(31.6 \%)$ & $4(44.4 \%)$ & \\
\hline No & $26(68.4 \%)$ & $5(55.6 \%)$ & \\
\hline HTN & & & 1.00 \\
\hline Yes & 19 (50\%) & $5(50 \%)$ & \\
\hline No & 19 (50\%) & $5(50 \%)$ & \\
\hline $\mathrm{DM}$ & & & .25 \\
\hline Yes & 19 (50\%) & $3(30 \%)$ & \\
\hline No & 19 (50\%) & $7(70 \%)$ & \\
\hline Charlson comorbidity Index & & & .92 \\
\hline 0 & $16(42.1 \%)$ & $5(45.5 \%)$ & \\
\hline 1 & $14(36.8 \%)$ & $4(36.4 \%)$ & \\
\hline 2 & $6(15.8 \%)$ & $1(9.1 \%)$ & \\
\hline 3 & $2(5.3 \%)$ & $1(9.1 \%)$ & \\
\hline ECOG PS & & & .19 \\
\hline 0 & $9(23.7 \%)$ & $2(18.2 \%)$ & \\
\hline 1 & $26(68.4 \%)$ & $6(54.5 \%)$ & \\
\hline 2 & $3(7.9 \%)$ & $2(18.2 \%)$ & \\
\hline 3 & 0 & $1(9.1 \%)$ & \\
\hline Family $\mathrm{Hx}$. of malignancy & & & .12 \\
\hline Yes & $7(18.4 \%)$ & 0 & \\
\hline No & $31(81.6 \%)$ & $11(100 \%)$ & \\
\hline Location of tumor & & & .85 \\
\hline Head & $26(68.4 \%)$ & $8(72.7 \%)$ & \\
\hline Body \& Tail & $12(31.6 \%)$ & $3(27.3 \%)$ & \\
\hline \multicolumn{4}{|c|}{ Preoperative data (median \pm SD) } \\
\hline $\mathrm{Hb}(\mathrm{g} / \mathrm{dL})$ & $12.5 \pm 1.5$ & $13.0 \pm 2.0$ & .46 \\
\hline INR & $1.04 \pm 0.19$ & $1.10 \pm 0.12$ & .57 \\
\hline T. Bil & $0.8 \pm 3.3$ & $0.7 \pm 1.1$ & .17 \\
\hline Albumin (g/dL) & $4.1 \pm 0.4$ & $4.1 \pm 0.4$ & .54 \\
\hline CA 19-9 (U/mL) & $175.0 \pm 713.8$ & $169.2 \pm 663.2$ & .98 \\
\hline TNM Staging & & & .32 \\
\hline 1 & $3(7.9 \%)$ & $2(18.2 \%)$ & \\
\hline 2 & $35(92.1 \%)$ & $9(81.8 \%)$ & \\
\hline
\end{tabular}

Table 1 Characteristics of patients with early stage pancreatic cancer $(N=49)$ (Continued)

\begin{tabular}{clll}
\hline Factors & $\begin{array}{l}\text { Surgery } \\
(N=38)\end{array}$ & $\begin{array}{l}\text { No surgery } \\
(N=11)\end{array}$ & $P$ value \\
\hline Yes & $10(26.3 \%)$ & $3(27.3 \%)$ \\
No & $28(73.7 \%)$ & $8(72.7 \%)$ \\
\hline
\end{tabular}

$B M I$ body mass index, ECOG Eastern Cooperative Oncology Group, PS performance status, $H x$. history, $S D$ standard deviation, $H b$ hemoglobin, INR international normalized ratio, $T$. Bil total bilirubin, CA 19-9 carbohydrate antigen 19-9, CTx. chemotherapy, $R T x$. radiotherapy

receive surgery due to a poor generalized state of health and 8 patients declined surgery or any other form of treatment. The median follow-up interval for all patients in the study $(n=49)$ was 12 months (range: 2-95 months), and the median survival time was $16 \pm 2.9$ months. The 1-year, 3-year, and 5-year survival rates were $58.5,20.2$, and $10.1 \%$, respectively.

\section{Comparisons of clinicopathological factors between the surgery group and no surgery groups}

Several clinicopathological factors were analyzed to compare differences between surgery group $(n=38)$ and no surgery group ( $n=11$; Table 1$)$. There was no significant difference in any factors analyzed. When we compared the OS rate, the surgery group showed a better prognosis than the no surgery group (log-rank test, $p=0.015$; Fig. 1). The median survival time after diagnosis was $17 \pm 5.5$ months and $10 \pm 2.8$ months for the surgery and no surgery groups, respectively. Overall, 24/38 (65.8\%) patients in the surgery group died due to tumor progression (vs. 11/11 in the no surgery group). The remaining $10 / 38$ patients died as a result of septic shock caused by bile peritonitis occurring after surgery $(n=1)$, severe pneumonia $(n=3)$ and an unknown cause without any clinical evidence of recurrence or progression of tumor $(n=6$; Table 2).

\section{Identification of factors for survival}

In univariate analysis, surgical resection (log-rank test, $p=0.015$ ) and Charlson comorbidity index (log-rank test, $p=0.044$ ) showed significance on OS (Table 3). And these two factors, not having undergone surgical resection [hazard ratio (HR) 2.412, $P=0.022$ ] and high Charlson comorbidity index (HR 5.252, $P=0.014$ ) were independent prognostic factors for poor OS in elderly patients with resectable pancreatic cancer (Table 4).

\section{Outcomes of patients who underwent surgery}

Among elderly patients with resectable pancreatic cancer, recurrences occurred in $27(71.1 \%)$ patients following surgery. The median disease-free survival times were 14 months (range, 1-103 months) in the surgery groups, respectively. The median survival times were 22 months and 14 months (range, 2-95 months), respectively. Severe postoperative 


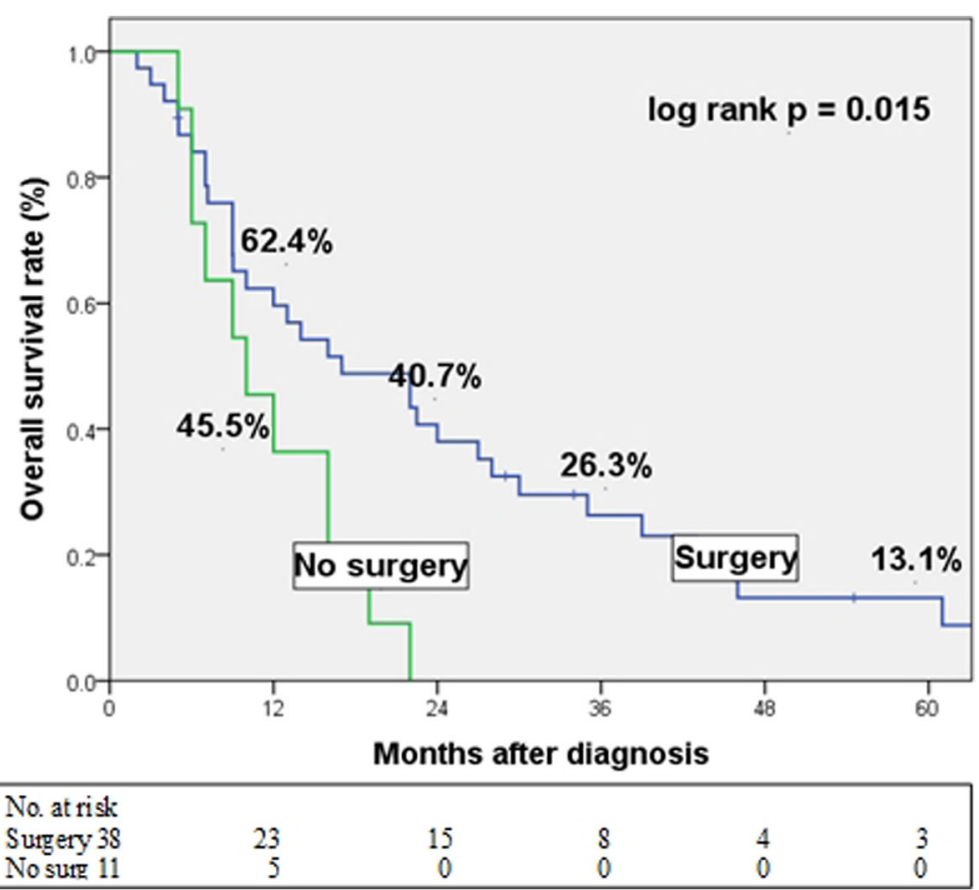

Fig. 1 Kaplan-Meier estimates for overall survival in elderly patients with resectable pancreatic cancer. Patients who underwent surgical resection had a better survival than those who did not undergo surgical resection $(p=0.015)$

complications (C-D classification III/IV) occurred in 12 (31.6\%) patients. Among the 4 patients who were alive at the last follow-up, only one patient had remained without disease for 95 months. Two had remained alive for 52 months and 27 months with recurrence in the liver detected at postoperative months 36 and 4, respectively. Lastly, one patient had remained alive for 31 months with peritoneal seeding, identified postoperative month 20 .

\section{Discussion}

Although surgical resection is the only curative treatment modality for pancreatic cancer, many elderly patients are not good candidates for surgery or decline surgery. Furthermore, they are less likely to receive other treatments including chemotherapy, compared with younger patients [16-18]. Because the population is aging, it is estimated that the number of elderly patients with pancreatic cancer will continue to rise [19]. In addition, life expectancy is increasing. In the

Table 2 Causes of death of patients with early stage pancreatic cancer

\begin{tabular}{lllc}
\hline Causes of death & Surgery $(N=38)$ & No surgery $(N=11)$ & $P$ value \\
\hline Not dead & $4(10.5 \%)$ & 0 & .18 \\
Operative mortality & $1(2.6 \%)$ & 0 & \\
Tumor progression & $24(65.8 \%)$ & $11(100 \%)$ & \\
Other causes & $9(26.4 \%)$ & 0 & \\
\hline
\end{tabular}

general population, the average life expectancy of an octogenarian is 7.44 years for males and 9.23 years for females according to the 2010 life-tables of the United States Social Security Administration [20]. It means that the number of elderly people can expect to live fairly longer. With advancements in surgical skills, devices, and perioperative management, the prognoses of many malignant diseases are improving. The prognosis of pancreatic cancer following various treatment modalities has also improved, although the degree of improvement is marginal [21]. Some authors reported worse prognosis among elderly patients following surgery compared with that among younger patients [22-24]. When we analyzed our data for overall patients who underwent surgery for resectable pancreatic cancer, we found that the median OS of elderly patients was significantly shorter than that of younger patients ( 16.0 vs. 23.4 months, $p=0.010$, data not shown). However, this result should not be considered as evidence for contraindicating surgery in elderly patients with pancreatic cancer because the life expectancy between the two age groups may be different. In this study, only patients with age more than 75 years were included. Many of the patients in the study were under the age of 80 years, so we analyzed the association between age and overall survival based on age 80 years. However, age was not a factor associated with overall survival in patients with resectable pancreatic cancer. 
Table 3 Univariate analysis of factors for overall survival in patients with early stage pancreatic cancer, Kaplan-Meier method

\begin{tabular}{lccc}
\hline Factors & No. of patients (\%) & $\begin{array}{l}\text { Median OS } \\
{[95 \% \mathrm{Cl}]}\end{array}$ & $\begin{array}{l}P \\
\text { value }\end{array}$ \\
\hline Sex & & .11
\end{tabular}

$\begin{array}{lll}\text { Male } & 32(65.3 \%) & 12.0[4.4-19.6] \\ \text { Female } & 17(34.7 \%) & 22.0[10.1-33.9]\end{array}$

Age

$\begin{array}{ll}75 \geq \text {, and }<80 & 38(77.6 \%) \\ \geq 80 & 11(22.4 \%) \\ \text { BMl } & \\ <25 & 43(87.8 \%) \\ \geq 25 & 6(12.2 \%)\end{array}$

Smoking

$\begin{array}{ll}\text { Yes } & 14(29.8 \%) \\ \text { No } & 33(70.2 \%)\end{array}$

Alcohol

$\begin{array}{cc}\text { Yes } & 16(34 \%) \\ \text { No } & 31(66 \%) \\ \text { HTN } & \\ \text { Yes } & 24(50 \%) \\ \text { No } & 24(50 \%) \\ \text { DM } & \\ \text { Yes } & 22(45.8 \%) \\ \text { No } & 26(54.2 \%)\end{array}$

Charlson comorbidity Index

0
1
2
3
ECOG
0
1
2
3
Family hx. of malignancy
Yes
No

\section{$21(42.9 \%)$ \\ $18(36.7 \%)$ \\ $7(14.3 \%)$ \\ $3(6.1 \%)$}

$11(22.4 \%)$

$32(65.3 \%)$

$4(8.2 \%)$

$2(4.1 \%)$

$7(14.3 \%)$

$42(85.7 \%)$

Location of tumor

\begin{tabular}{|c|c|}
\hline \multicolumn{2}{|l|}{ Head } \\
\hline \multicolumn{2}{|c|}{ Body \& Tail } \\
\hline \multicolumn{2}{|c|}{$\mathrm{tb}(\mathrm{g} / \mathrm{dL})$} \\
\hline$\geq 13$ & 19 (38.8\%) \\
\hline$<13$ & $30(61.2 \%)$ \\
\hline \multicolumn{2}{|l|}{ TT (INR) } \\
\hline$\leq 1.2$ & 43 (93.5\%) \\
\hline
\end{tabular}

$19.0[12.5-25.5]$

9.0 [0.7-17.3]

16.0 [5.7-26.3]

$6.0[4.4-7.6]$

22.0 [12.6-31.4]

14.0 [7.3-20.7]

$5.0[2.1-7.9]$

6.0

9.0 [6.4-11.6]

16.0 [8.5-23.5]

12.0 [6.3-17.7]

19.0 [2.6-35.4]

$16.0[6.2-25.8]$

$13.0[2.5-23.5]$
Table 3 Univariate analysis of factors for overall survival in patients with early stage pancreatic cancer, Kaplan-Meier method (Continued)

\begin{tabular}{|c|c|c|c|}
\hline Factors & No. of patients (\%) & $\begin{array}{l}\text { Median OS } \\
{[95 \% \mathrm{Cl}]}\end{array}$ & $\begin{array}{l}P \\
\text { value }\end{array}$ \\
\hline$>1.2$ & $3(6.5 \%)$ & $9.0[4.2-13.8]$ & \\
\hline T. Bil & & & .92 \\
\hline$\leq 1.2$ & $32(65.3 \%)$ & 16.0 [6.3-25.7] & \\
\hline$>1.2$ & 17 (34.7\%) & 14.0 [10.2-17.9] & \\
\hline Albumin (g/dL) & & & .55 \\
\hline$\geq 3.3$ & $45(91.8 \%)$ & 16.0 [10.8-21.2] & \\
\hline$<3.3$ & $4(8.2 \%)$ & $12.0[0.0-24.0]$ & \\
\hline CA 19-9 (U/mL) & & & .38 \\
\hline$\leq 37$ & $14(29.2 \%)$ & 10.0 [8.3-11.8] & \\
\hline$>37$ & $34(70.8 \%)$ & 16.0 [10.4-21.6] & \\
\hline Stage & & & .12 \\
\hline 1 & $5(10.2 \%)$ & $22.5[15.0-30.0]$ & \\
\hline 2 & $44(89.8 \%)$ & $13.0[7.5-18.5]$ & \\
\hline Surgical resection & & & .02 \\
\hline Yes & $38(77.6 \%)$ & 16.0 [5.1-26.9] & \\
\hline No & $11(22.4 \%)$ & $10.0[4.6-15.4]$ & \\
\hline CTx. and/or RTx. & & & .09 \\
\hline Yes & 17 (34.7\%) & $22.0[8.6-35.4]$ & \\
\hline No & $32(65.3 \%)$ & $10.0[4.6-15.4]$ & \\
\hline
\end{tabular}

No. number, OS overall survival, $C l$ confidence interval, $B M I$ body mass index, ECOG Eastern Cooperative Oncology Group, PS performance status, $H x$. history, $S D$ standard deviation, $\mathrm{Hb}$ hemoglobin, INR international normalized ratio, $T$. Bil total bilirubin, CA 19-9 carbohydrate antigen 19-9, CTx. chemotherapy, $R T x$. radiotherapy

Recently, some authors have reported that elderly patients who underwent surgical resection for pancreatic cancer showed outcomes comparable to those shown by younger patients $[19,25,26]$.

As discussed above, the benefits of surgical resection for pancreatic cancer in elderly patients are controversial. Therefore, comparing the outcomes of elderly patients based on whether surgical resection was undertaken or not may be more suitable to identify the benefits of surgery in elderly patients than comparing age groups. However, there have been few studies comparing the prognosis in elderly patients with resectable pancreatic cancer between surgery and no surgery groups. In a study reported by He et al., patients who underwent surgery for resectable pancreatic cancer had a significantly higher 5 -year OS rate $(25.0$ vs $2.3 \% ; P<0.0001)$ and a higher median survival time ( 24.3 vs 5.8 months) compared with patients who did not undergo surgery [27]. This result gives more weight to the assertion that age alone should not be a contraindication to surgery in elderly patients with pancreatic cancer. Clinicians need to more formally assess the individual operability in terms 
Table 4 Multivariate analysis for overall survival of patients with early stage pancreatic cancer

\begin{tabular}{lcclll}
\hline Factors & $\begin{array}{c}P \text { - } \\
\text { value }\end{array}$ & OR & & $95.0 \% \mathrm{Cl}$ & \\
\cline { 5 - 6 } & & & Min. & Max. \\
\hline $\begin{array}{l}\text { Surgical resection } \\
\text { Yes }\end{array}$ & .02 & & & \\
$\quad$ No & & 2.41 & 1.13 & 5.11 \\
Charlson comorbidity Index & .10 & & & \\
0 & & 1 & Reference & Reference \\
1 & .48 & 1.28 & 0.63 & 2.57 \\
2 & .94 & 1.03 & 0.42 & 2.49 \\
3 & .01 & 5.25 & 1.39 & 19.76 \\
\hline
\end{tabular}

OR odds ratio, Min. minimum, Max. maximum

of comorbidities, cognitive status, preoperative functional status, and frailty [28]. For patients and their relatives, it is important that they understand the risk of mortality, complications, and need for skilled nursing care after pancreatic surgery when making this decision, but it is equally important that they understand the benefit of surgical resection and that this benefit is not significantly diminished with increasing age despite the greater short-term complications [29].

We identified that surgical resection and Charlson comorbidity index were independent risk factors for OS in elderly patients with resectable pancreatic cancer. Surgical resection is well-known as the only curative treatment modality for resectable pancreatic cancer. The relation between a high Charlson comorbidity index and poor prognosis is supported by a study reported by Asano et al. which showed that the OS rate was significantly higher in the low Charlson age comorbidity index group than in the high Charson comorbidity index group $(P=0.047)$, and a high Charlson age comorbidity index was an independent factor of poor survival $(P=$ 0.024) [30].

This study has some limitations. First, as with all retrospective studies, there may have been a selection bias regarding the diagnosis and treatment of patients with pancreatic cancer. Quality of life, another important outcome of patients with pancreatic cancer could not be evaluated due to the retrospective nature of this study. In addition, the number of cases was small despite a study period of $>10$ years, reflecting the fact that elderly patients with resectable pancreatic cancer are rare. For example, the distribution of the ECOG PS score was different between two groups in this study. However, there was no statistical significant difference. Although there was a just one patient with ECOG PS 3 in 'No surgery group, it might affect poor outcome in 'No surgery group'. There is a limitation to assessing the degree of the impact of this difference in small-scale study. Thus, meaningful statistical analysis was challenging, which may be overcome by performing a multicenter study in the future. We were also unable to compare the efficacy between multimodal and unimodal treatment of resectable pancreatic cancer with or without surgery because of the lack of evidence as to which treatment is better; this is possibly because it depends on the clinical state of each patient. Further studies are necessary to validate the various treatment modalities. Finally, despite the small number of patients, the strategy of treatment modalities applied was heterogeneous. This might be due to the poor prognosis with short survival time of pancreatic cancer and the various degrees of positivity pertaining to the treatment of patients.

\section{Conclusions}

In conclusion, whether surgical resection was performed or not and the Charlson comorbidity index were independent risk factors for OS in elderly patients with resectable pancreatic cancer. Therefore, except for those with a high Charlson comorbidity index, aggressive surgical approach seems beneficial for elderly patients with resectable pancreatic cancer.

\section{Abbreviations \\ CT: Computed Tomography; DP: Distal Pancreatectomy; ECOG: Eastern Cooperative Oncology Group; HR: Hazard Ratio; MRI: Magnetic Resonance Imaging; OS: Overall Survival; PD: Pancreaticoduodenectomy; PPPD: Pylorus Preserving Pancreaticoduodenectomy; PS: Performance Status; TP: Total Pancreatectomy}

\section{Acknowledgements}

The authors thank SA Lee and EK Hong for their valuable contribution to the data processing. They also thank SM Woo and WJ Lee for their advice on the manuscript.

\section{Authors' contributions}

SJP conducted the experiments. HMP participated in collecting the data and drafted the manuscript. HMP and SJP contributed to the statistical analysis and manuscript writing. SSH, SHK, and SJP conceived the present study and helped revise the manuscript. All authors read and approved the final manuscript.

\section{Funding}

This work was supported by National Cancer Center Research Grant 1910990 and 1810864 .

\section{Availability of data and materials}

The datasets used and/or analysed during the current study are available from the corresponding author on reasonable request.

\section{Ethics approval and consent to participate}

The study was conducted in accordance with the Ethics Committee of the National Cancer Center, Korea) and the 1964 Helsinki Declaration. Because this retrospective studies were conducted on elderly patients with pancreatic cancer, most patients died and couldn't write consent forms. In addition, survivors also ended their monitoring due to old age, so we asked for an exemption from writing consent forms to Ethics Committee of the National Cancer Center, Korea. And Ethics Committee of the National Cancer Center, Korea approved this procedure (NCC2019-0061).

Consent for publication

Not applicable. 


\section{Competing interests}

The authors declare that they have no competing interests.

Received: 5 February 2019 Accepted: 14 October 2019

Published online: 12 November 2019

\section{References}

1. Siegel RL, Miller KD, Jemal A. Cancer statistics, 2017. CA Cancer J Clin. 2017; 67(1):7-30.

2. Gleisner AL, Spolverato G, Ejaz A, Pawlik TM. Time-related changes in the prognostic significance of the total number of examined lymph nodes in node-negative pancreatic head cancer. J Surg Oncol. 2014;110(7):858-63.

3. Winter JM, Brennan MF, Tang LH, D'Angelica Ml, Dematteo RP, Fong Y, et al. Survival after resection of pancreatic adenocarcinoma: results from a single institution over three decades. Ann Surg Oncol. 2012;19(1):169-75.

4. Lee DY, Schwartz JA, Wexelman B, Kirchoff D, Yang KC, Attiyeh F. Outcomes of pancreaticoduodenectomy for pancreatic malignancy in octogenarians: an American College of Surgeons National Surgical Quality Improvement Program analysis. Am J Surg. 2014;207(4):540-8.

5. Lightner AM, Galsgow RE, Jordan TH, Krassner AD, Way LW, Mulvihill SJ, et al. Pancreatic resection in the elderly. J Am Coll Surg. 2004;198(5):697-706.

6. Bathe OF, Levi D, Caldera H, Franceschi D, Raez L, Patel A, et al. Radical resection of periampullary tumors in the elderly: evaluation of long-term results. World J Surg. 2000;24(3):353-8.

7. Casadei R, Ricci C, Lazzarini E, et al. Pancreatic resection in patients 80 years or older: a meta-analysis and systematic review. Pancreas. 2014:43(8):1208-18.

8. Mauriello C, Polistena A, Gambardella C, Taffurelli G, D'Ambra M, Mastroroberto $\mathrm{M}$, et al. Pancreatic stump closure after pancreatoduodenectomy in elderly patients: a retrospective clinical study. Aging Clin Exp Res. 2016 Nov;11 [Epub ahead of print].

9. Brahmbhatt B, Bhurwal A, Lukens FJ, Buchanan MA, Stauffer JA, Asbun HJ. Pancreatic surgery in the older population: a single Institution's experience over two decades. Curr Gerontol Geriatr Res. 2016 Nov;27 [Epub ahead of print].

10. Okabayashi T, Shima Y, Iwata J, Morita S, Sumiyoshi T, Kozuki A, et al. Is a surgical approach justified for octogenarians with pancreatic carcinoma? Projecting surgical decision making for octogenarian patients. Am J Surg. 2016;212(5):896-902

11. Marmor S, Burke EE, Virnig BA, Jensen EH, Tuttle TM. A comparative analysis of survival outcomes between pancreatectomy and chemotherapy for elderly patients with adenocarcinoma of the pancreas. Cancer. 2016;122(21): 3378-85.

12. Oken MM, Creech RH, Tormey DC, Horton J, Davis TE, McFadden ET, et al. Toxicity and response criteria of the eastern cooperative oncology group. Am J Clin Oncol. 1982;5(6):649-55.

13. Charlson M, Szatrowski TP, Peterson J, Gold J. Validation of a combined comorbidity index. J Clin Epidemiol. 1994;47(11):1245-51.

14. Quan H, Li B, Couris CM, Fushimi K, Graham P. Hider P, et al. Updating and validating the Charlson comorbidity index and score for risk adjustment in hospital discharge abstracts using data from 6 countries. Am J Epidemiol. 2011;173(6):676-82.

15. Dindo D, Demartines N, Clavien PA. Classification of surgical complications: a new proposal with evaluation in a cohort of 6336 patients and results of a survey. Ann Surg. 2004;240(2):205-13.

16. Bouchardy C, Rapiti E, Blagojevic S, Vlastos AT, Vlastos G. Older female cancer patients: importance, causes, and consequences of undertreatment. J Clin Oncol. 2007;25(14):1858-69.

17. Quaglia A, Tavilla A, Shack L, Brenner H, Janssen-Heijnen M, Allemani C, et al. The cancer survival gap between elderly and middle-aged patients in Europe is widening. Eur J Cancer. 2009;45(6):1006-16.

18. King JC, Zenati M, Steve J, Winters SB, Bartlett DL, Zureikat AH, et al. Deviations from expected treatment of pancreatic Cancer in octogenarians: analysis of patient and surgeon factors. Ann Surg Oncol. 2016;23(13):4149-55.

19. Higuera O, Ghanem I, Nasimi R, Prieto I, Koren L, Feliu J. Management of pancreatic cancer in the elderly. World J Gastroenterol. 2016;22(2):764-75.

20. Bell FC, Miller LM. Life tables for the United States Social Security area 19002100., S.S. Administration, Editor Aug 2005, Social Security Administration 2005; 11-11536

21. Serrano PE, Cleary SP, Dhani N, Kim PT, Greig PD, Leung K, et al. Improved long-term outcomes after resection of pancreatic adenocarcinoma: a comparison between two time periods. Ann Surg Oncol. 2015;22(4):1160-7.
22. Targarona J, Callacondo D, Pino C, Rodriguez C, Coayla G, Garatea R, et al. Impact of duodenopancreatectomy in elder patients. Rev Gastroenterol Peru. 2013;33(3):217-22.

23. Finlayson $\mathrm{E}$, Fan Z, Birkmeyer JD. Outcomes in octogenarians undergoing high-risk cancer operation: a national study. J Am Coll Surg. 2007;205(6): 729-34.

24. Sho M, Murakami Y, Kawai M, Motoi F, Satoi S, Matsumoto I, et al. Prognosis after surgical treatment for pancreatic cancer in patients aged 80 years or older: a multicenter study. J Hepatobiliary Pancreat Sci. 2016;23(3):188-97.

25. Bergquist JR, Shubert CR, Ubl DS, Thiels CA, Kendrick M, Truty MJ, et al. Risk by indication for pancreaticoduodenectomy in patients 80 years and older: a study from the American College of Surgeons National Surgical Quality Improvement Program. HPB (Oxford). 2016;18(11):900-7.

26. Renz BW, Khalii PN, Mikhailov M, Graf S, Schiergens TS, Niess H, et al. Pancreaticoduodenectomy for adenocarcinoma of the pancreatic head is justified in elderly patients: a retrospective cohort study. Int I Surg. 2016;28: $118-25$.

27. He W, Zhao H, Chan W, Lopez D, Shroff RT. Giordano, S. H.. underuse of surgical resection among elderly patients with early-stage pancreatic cancer Surgery. 2015;158(5):1226-34.

28. Riall TS. What is the effect of age on pancreatic resection? Adv Surg. 2009; 43:233-49.

29. Riall TS, Sheffield KM, Kuo YF, Townsend CM, Goodwin JS. Resection benefits older adults with locoregional pancreatic cancer despite greater short-term morbidity and mortality. J Am Geriatr Soc. 2011;59(4):647-54.

30. Asano T, Yamada S, Fujii T, Yabusaki N, Nakayama G, Sugimoto H. et al. The Charlson age comorbidity index predicts prognosis in patients with resected pancreatic cancer. Int J Surg 2017 02. [Epub ahead of print].

\section{Publisher's Note}

Springer Nature remains neutral with regard to jurisdictional claims in published maps and institutional affiliations.

Ready to submit your research? Choose BMC and benefit from:

- fast, convenient online submission

- thorough peer review by experienced researchers in your field

- rapid publication on acceptance

- support for research data, including large and complex data types

- gold Open Access which fosters wider collaboration and increased citations

- maximum visibility for your research: over $100 \mathrm{M}$ website views per year

At $\mathrm{BMC}$, research is always in progress.

Learn more biomedcentral.com/submissions 